\title{
El imaginario tecnológico de Domingo Faustino Sarmiento: representaciones y arquetipos de América (1845-1885)/
}

\section{The technological imaginary of Domingo Faustino Sarmiento: representations and archetypes of America (1845-1885)}

\author{
José Manuel Azcona Pastor \\ y Víctor Guijarro Mora \\ Universidad Rey Juan Carlos
}

El artículo examina la dimensión técnica del imaginario de Domingo Faustino Sarmiento y su influencia en la construcción de representaciones sobre la naturaleza, los tipos humanos, el progreso de las naciones, la educación y los personajes científicos. Como se verá, el influyente estadista argentino crea desde una mirada tecnologista una amplia variedad de imágenes y arquetipos que pueden reconocerse en diversas obras. El propósito del trabajo es pues la presentación de estos símbolos como un resultado de su actitud tecnológica y su exposición siguiendo una división que comprende cuatro categorías: la primera dedicada a las imágenes de una naturaleza hostil; la segunda a los arquetipos humanos; la tercera a las naciones modelo (en especial, como resultado de su viaje a Estados Unidos) y la cuarta al tratamiento de la figura del científico y del tecnólogo como héroes y agentes del progreso.

Palabras ClaVe: Tecnología; Imaginación; Domingo Faustino Sarmiento; Siglo XIX; Iberoamérica; Tecnologismo; Naturaleza; Civilización; Progreso; Tipos humanos.

The paper explores the technical dimension of Domingo Faustino Sarmiento's imaginary and its influence on the construction of representations concerning nature, human types, progress of nations, and scientific personalities. As we will see, the influential Argentine statesman and writer creates, from a technologistic perspective, a wide variety of images and archetypes which can be traced in different publications. The aim of this paper is then to present these different types of symbolic features as a result of his technological attitude and to expose them according to a division that comprises four categories: the first one is devoted to images of an hostile nature; the second one examines the human archetypes he considers; the third one deals with the model nations (in particular, as a result of his trip to the United States), and the fourth one focuses on the treatment of scientists and engineers as heroes and agents of progress.

KeYwords: Technology; Imagination; Domingo Faustino Sarmiento; 19th Century; Latin America; Technologicism; Nature; Civilization; Progress; Human types. 


\section{Introducción ${ }^{1}$}

Es ya conocida la influencia que tanto el socialismo utópico como el liberalismo ejercieron sobre una generación de intelectuales latinoamericanos con ambiciones políticas y con deseos de consumar la emancipación tanto política como mental de la etapa colonial. En este proceso se sustituyó a España por Francia, Inglaterra y Estados Unidos. ${ }^{2}$ Entre ellos destaca el argentino Domingo Faustino Sarmiento, quien compartía, como es sabido, los intereses del movimiento romántico de la Generación de 1837, integrada por figuras como Esteban Echeverría, Juan María Gutiérrez y Marcos Sastre. ${ }^{3}$ Estas concepciones se combinaron, más adelante, con algunas aportaciones del positivismo, del darwinismo social y de las corrientes antropológicas que defendían el determinismo natural de las culturas. ${ }^{4} \mathrm{~A}$ partir de las correspondencias entre esos saberes y actitudes de la élite y su fascinación por la tecnología como instrumento de progreso y civilización, Sarmiento nos desvela un mundo diverso de representaciones y arquetipos. La mirada de los objetos, de la naturaleza, de las grandes construcciones, así como de la ciudad y de los agentes del progreso que aparece en diversas obras escritas entre 1840 y 1885 tiene significado si atendemos a la dimensión simbólica que el autor atribuye a la práctica tecnológica. Más allá pues de las contradicciones entre los textos de Sarmiento y los contextos sociales y económicos, que alguna vez aparecen mencionadas en el presente trabajo, el estudio se centra en la experiencia sarmientina según se muestra en sus escritos. De esta forma, el imaginario y en particular su dimensión técnicosimbólica, se proponen como objeto de análisis histórico, siguiendo así los planteamientos que Beatriz Sarlo presenta en La imaginación técnica. ${ }^{5}$

1 Los autores queremos mostrar nuestro agradecimiento a Leoncio López-Ocón, Leonor González, Josu Ruiz de Gordejuela y Matteo Re, quienes con sus aportaciones han contribuido a mejorar y enriquecer las versiones previas de este trabajo.

2 Larrain, 2005, 77.

3 Sobre esta etapa, Rama, 1977 y Zea, 1976; para una introducción general a su pensamiento, Sorensen, 2002, «Introducción».

4 La influencia positivista se refleja en su insistencia en la figura del científico y del tecnólogo como modelo de santidad laica, así como en la defensa de la educación práctica; el darwinismo social, por su parte, se advierte en su defensa de la supervivencia de las culturas en función de su posición más o menos ventajosa en el mercado internacional.

5 Sarlo, 2004, 9-17. Mediante este trabajo se pretende de igual manera aportar información a los estudios culturales que centran su interés en los propósitos ideales asociados con determinadas prácticas de la tecnología; sobre la dimensión simbólica de la tecnología y su distinción de la función económica e intelectual, Pacey, 1980, 9-18; pueden incluirse en este tipo de enfoques la obras de Marx, 1964; Kasson, 1999; Nye, 1997. 
Para examinar la posición de Sarmiento en este escenario atenderemos a las siguientes divisiones: 1) las representaciones de la naturaleza, donde incluimos la visión del desierto y la pampa, la amenaza del mundo natural y el contraste entre el paisaje rural y el urbano; 2) los tipos humanos: el «industrioso» que domina la técnica frente al «indio» (el hacendoso frente al perezoso; la rapidez y el dinamismo frente a la lentitud y la inmutabilidad); 3) las naciones ideales, donde destacamos particularmente las impresiones de su viaje a Estados Unidos y 4) los santos laicos: la atención a las vidas ejemplares de científicos y tecnólogos.

\section{Visiones: las fronteras de la civilización}

Al describir el paisaje argentino, Sarmiento en Civilización y barba$r i e^{6}$ se refiere a las amplias zonas despobladas, así como al predominio de la llanura, el bosque y el desierto. «El mal que aqueja a la República Argentina - dice- es la extensión; el desierto la rodea por todas partes, se le insinúa en las entrañas; la soledad, el despoblado sin una habitación humana, son por lo general los límites incuestionables entre unas y otras provincias». ${ }^{7}$ Son lugares inseguros y hostiles, inmensos porque no hay formas de comunicación ni acción humana, donde las pequeñas poblaciones de campesinos y ganaderos viven con la amenaza de la proximidad del salvaje o la inquietud por la presencia de un tigre o de una víbora que lo acecha. Una excepción en el horizonte desalentador son sus ríos navegables. Las vías fluviales, comenta Sarmiento, no han sido explotadas porque a los españoles no les fue dado el instinto de la navegación, que sí poseen en cambio los «sajones del Norte». Este espíritu contrasta con el propio de la pampa, dominado por la barbarie. ${ }^{8}$ Imagina el autor que «En la solitaria caravana de carreteras que atraviesa pesadamente las pampas, y que se detiene a reposar por momentos, la tripulación, reunida

6 Sarmiento, 2002, 543-559.

7 Ibidem, 544.

8 Ibidem, 545. Toma este término probablemente, según Graciela Scheines, del jesuita Pedro Lozano (1697-1752), quien lo usa como sustantivo en Descripción chorográfica del Gran Chaco para definir la geografía americana; dice Scheines sobre su cambio de significado: «Si en su origen la palabra fue adjetivo aplicado a lo humano, ahora es sustantivo, una geografía fuerte que determina a sus habitantes» (Scheines, 1991, 45-46). 
en torno del escaso fuego, vuelve maquinalmente la vista hacia el sur al más ligero susurro del viento que agita las yerbas secas, para hundir sus miradas en las tinieblas profundas de la noche en busca de los bultos siniestros de la horda salvaje que puede sorprenderla desapercibida de un momento a otro». ${ }^{9}$ En la sección dedicada a describir los caracteres argentinos cita el poema de Echeverría La cautiva (1837), donde con tintes románticos se narra la lucha de María, el personaje central, contra el cautiverio al que está sometida junto con su marido por los indios; allí el desierto (primera parte del poema), el llano y la pampa tienen vida propia, y en estos lugares es donde campa «la insensata turba [que] con su alarido perturba las calladas soledades [...] el bando de salvajes, atronando el campo convecino $[\ldots] \gg .{ }^{10}$ Es el indio sanguinario que asola la civilización. El estado natural es pues sinónimo de barbarie y esta situación sólo podrá superarse mediante la tecnificación, equivalente a su vez a la acción civilizadora.

Según L. Urteaga, durante la Ilustración se extendió una visión economicista del entorno natural que, en una de sus variantes, el enfoque progresista, entendía la naturaleza como un obstáculo. ${ }^{11}$ Subraya de igual manera Leila Gómez en Iluminados y tránsfugas el contraste entre la visión de la naturaleza de los escritores románticos norteamericanos (en particular los vinculados al transcendentalismo, como Ralph Waldo Emerson y Henry David Thoreau) y la de Sarmiento. «Para el trascendentalismo - según afirma la autora-, la naturaleza del nuevo continente se presenta como un desafío intelectual y espiritual más que como una fuerza antagónica y barbárica». ${ }^{12}$ Pero además en las visiones sarmientinas se reproducen modelos arraigados en tradiciones culturales anteriores. Dice R. Bartra en El mito del salvaje que en la cultura judeocristiana el desierto era un «espacio de tentación y de prueba, de peligro y de éxtasis, de

9 Ibidem, 544.

10 Echeverría, 1991; en el poema aparecen también escenas en las que indios borrachos absorben la sangre de un caballo con un corte de cuchillo en el cuello: «Aquél come, éste destriza,/más allá alguno degüella/con afilado cuchillo/la yegua al lazo sujeta,/y a la boca de la herida,/por donde ronca y resuella,/y a borbollones arroja/la caliente sangre fuera,/en pie, trémula y convulsa,/dos o tres indios se pegan/como sedientos vampiros, sorben, chupan, saborean/la sangre, haciendo mormullo,/y de sangre se rellenan (Segunda parte, «El festín»). La novela Amalia (1851) de José Mármol emplea también la oposición barbarie-civilización para situar la historia de unos personajes amenazados por la pampa, los gauchos y los indios, Larrain, 2005, 87.

11 Urteaga, 1987, 35.

12 Gómez, 2009, 54. 
muerte y de promesas». ${ }^{13}$ Aunque este dominio natural no fuera necesariamente salvaje, sus manifestaciones adquirían formas amenazadoras, ya fuera por el predominio de la soledad o por su vaciedad. En medio del desierto es donde, según el Antiguo Testamento, Yahveh coloca el jardín del Edén, del que son expulsados Adán y Eva al territorio agreste y que deben domesticar con pesadumbre. No hay que olvidar que en la concepción hebrea el desierto era un concepto moral; era un castigo o una prueba: «El verdadero sufrimiento de vivir en el desierto salvaje no es físico, sino moral». ${ }^{14}$

El contraste entre el medio rural y el urbano sirve a Sarmiento para insistir en los argumentos ya expuestos. La ciudad es el «centro de la civilización argentina, española, europea», donde «están los talleres de las artes, las tiendas del comercio, las escuelas y colegios, los juzgados, todo lo que caracteriza, en fin, los pueblos cultos». El desierto, «llano inculto de centenares de millas cuadradas», rodea a estos enclaves privilegiados. ${ }^{15}$ También campos extensos circundan la ciudad. Pero donde no hay urbes, con su fisonomía regular y sus calles ordenadas según ángulos rectos, el progreso moral es imposible, la civilización no se consigue y la barbarie es el recurso común. Incluso en el interior de las ciudades, como se verá en el caso de Valparaíso, hay contrastes: la agitación del puerto se opone a la lentitud del fango que llena sus calles. Son enclaves urbanos que aún no han conseguido acercarse a la geometría de París ${ }^{16}$ ni a producir la sensación que en 1846 le provocaba la capital francesa, cuando después de sus paseos escribía: «Je flâne, yo ando como un espíritu, como un elemento, como un cuerpo sin alma en esta soledad de París. Ando lelo; paréceme que no camino, que no voy sino que me dejo ir, que floto de las aceras a los bulevares». ${ }^{17}$

13 Bartra, 2011, 52.

14 Ibidem.

15 Sarmiento, 2002, 552. Otras afirmaciones similares aparecen en páginas posteriores, como que en las llanuras argentinas «la sociedad ha desaparecido completamente, queda sólo la familia feudal, aislada, reconcentrada; y no habiendo sociedad reunida, toda clase de gobierno se hace imposible... Es, en fin, algo parecido a la feudalidad de la Edad Media, en que los barones residían en el campo, y desde allí hostilizaban las ciudades y asolaban las campañas, pero aquí faltan el barón y el castillo feudal» (Ibidem., 554-555).

16 Solamente Buenos Aires, en contraste con Córdoba, se acerca a la utopía (Scheines, 1991, 54-56).

17 «Viajes por Europa, África y América», Ibidem, 330. 
Después de ser apresado y obligado a exiliarse, Sarmiento se trasladó a Chile en 1840. De este país le llamó especialmente la atención la dinámica Valparaíso. La ciudad se había convertido desde finales del siglo XVIII en uno de los enclaves portuarios más importantes para los buques que, atravesando el Cabo de Hornos, seguían la ruta que comunicaba Europa con la costa del Pacífico. Contaba por ello con una próspera actividad comercial. Emprendedores procedentes de diversos países, algunos del Viejo Continente, habían establecido en el lugar sus negocios. Sarmiento ordenó sus impresiones sobre la ciudad para conformar un texto inscrito en la literatura de viajes. Pero en este caso lo que le llama la atención son las costumbres, miserias del lugar y los paisajes artificiales. Durante las primeras décadas del siglo XIX adquirieron una cierta popularidad, especialmente en Inglaterra (el «taller del mundo»), las guías de viajes industriales, algo inconcebible en épocas anteriores. Se trataba de mostrar los logros de la habilidad y de la inteligencia humanas, una propuesta que se encuentra recogida, por señalar dos ejemplos, en las obras de W. Cooke Taylor, Notes of a Tour in the Manufacturing Districts of Lancashire (Londres, 1842) o la de B. Love, The hand-book of Manchester (Manchester, 1842, 2.. ed.). ${ }^{18}$ Mientras que en éstas el propósito se muestra de manera explícita, en el texto de Sarmiento aparece de una manera tácita, acompañada de la firme intención de denunciar unas impresiones que le incomodan.

El Valparaíso que se inventa Sarmiento tiene un punto de partida recurrente, el contraste entre esta ciudad, próspera y cosmopolita, y los pueblos del interior, anunciado ya en las primeras líneas de su escrito. ${ }^{19}$ Pero las oposiciones están presentes igualmente en el interior de la propia urbe. El relato comienza con el penoso traslado a una posada, donde coincide con «dos ingleses»y un «francés». Los primeros hablan de los «caminos de vapor y los carriles macadamizados» $; 20$ el segundo de la excelencia de los caminos de Francia. ${ }^{21}$ La alusión a la tecnología de las comunicaciones tiene el propósito de reforzar el contraste entre la modernidad, el progreso y la civilización y el atraso de los caminos de fango por donde ha transitado,

18 Schaffer, 1994, 203-216.

19 D. Faustino Sarmiento, «Un viaje a Valparaíso», Mercurio, Septiembre de 1841, en Sarmiento, 2002, 130.

20 La última técnica, que se debe al ingeniero escocés J. L. Mac Adam, 1756-1836, se refiere al pavimento con macadam, compuesto de piedra machacada que se extiende y posteriormente se comprime con rodillo.

21 Sarmiento, «Un viaje a Valparaíso», Sarmiento, 2002, 137. 
símbolos de la «rudeza inculta de nuestra América». Pero ante todo, lo relevante del Valparaíso según lo concibe Sarmiento es que

\begin{abstract}
Allí viven extranjeros opulentos; hay un gobierno ilustrado y anheloso por la mejora del país; hay un pueblo civilizado que quisiera dar a sus huéspedes la más ventajosa idea de su cultura, civilización y costumbres; hay comercio que hace apreciar lo que las vías de comunicación influyen en la riqueza pública; hay gente educada, en fin, y sus costumbres a la europea y las calles serán modelo de policía, aseo y esmero, digno de proponerse a la imitación de las demás ciudades del interior que conservan más arraigados sus hábitos coloniales. ${ }^{22}$
\end{abstract}

Observa unos pabellones de colores empleados por los europeos como almacenes e imagina que albergan diversos productos de la industria, que son los «resultados gigantescos de su ciencia». Además de responder a los intereses materiales, el movimiento de mercancías y buques que se lleva a cabo en el puerto tiene un efecto moral que contribuye a impulsar la riqueza nacional y el desarrollo de la inteligencia. Viene a continuación un alegato a favor de la actividad comercial, garante, según sostiene, de la libertad y de la mejora social. Y seguidamente destaca los rótulos de almacenes, registros y tiendas que se encuentra a su paso: Burnet \& Co., J. \& A. Grogan, Good Habanah cigars, Chandleers oil and colour stores, Best beer \& cigars of all kinds, ... en definitiva, para Sarmiento la utopía se sustenta, como se advierte en su Argirópolis o la Capital del Río de la Plata (1850), en la idea de ocupar el espacio mediante la urbanización ${ }^{23} \mathrm{o}$ bien en cercar los campos mediante alambres. «iCerquen, no sean bárbaros!», decía Sarmiento a los propietarios de tierras. ${ }^{24}$

\title{
Arquetipos humanos
}

Sarmiento se sirve de la categoría de raza como grupo humano cultural y originariamente diferenciado para enfatizar las insalvables diferencias de su país. A esta categoría se asocian rasgos físicos y rasgos morales: la diligencia, el dinamismo y la innovación (tipos humanos industriosos) frente a la inactividad, la indolencia y la inmutabilidad (tipos

22 Ibidem, 142.

23 Amaro, 2003.

24 Años más tarde, las firmas H. Henneberg \& Co. y Justo y Ackermann empleaban el nombre «Sarmiento» en una marca de alambre destinada a este fin (Reggini, 1997, 18). 
indígenas). Afirma que en la pampa prevalece un pueblo compuesto de dos razas mezcladas, la española y la indígena. En las áreas rurales de Córdoba y San Luis predomina la raza española pura; en Santiago del Estero los habitantes hablan el quechua, lo que revela su origen indio. En cuanto a la raza negra, extinta excepto en Buenos Aires, añade que es «el eslabón que une al hombre civilizado con el palurdo; raza inclinada a la civilización, dotada de talento y de los más bellos instintos de progreso» ${ }^{25} \mathrm{Y}$ comenta seguidamente:

Por lo demás, de la fusión de las estas tres familias ha resultado un todo homogéneo que se distingue por su amor a la ociosidad e incapacidad industrial, cuando la educación y las exigencias de una posición social no vienen a ponerle espuela y sacarla de su paso habitual. Mucho debe haber contribuido a producir este resultado desgraciado la incorporación de indígenas que hizo la colonización. Las razas americanas viven en la ociosidad, y se muestran incapaces, aun por medio de la compulsión, para dedicarse a un trabajo duro y seguido. Esto sugirió la idea de introducir negros en América, que tan fatales resultados ha producido. Pero no se ha mostrado mejor dotada de acción la raza española cuando se ha visto en los desiertos americanos abandonada a sus propios instintos. ${ }^{26}$

Sarmiento asegura que las debilidades de estas razas son más evidentes cuando se las compara con el acierto, comprobado en viviendas y manufacturas, de las colonias alemana y escocesa establecidas en el sur de Buenos Aires.

La predisposición a la innovación está igualmente condicionada por factores culturales. En este caso, el habitante de la pampa, el gaucho, se compara en varias ocasiones con el nativo de los pueblos de cultura islámica. ${ }^{27}$ De estos últimos incluso destaca que tienen rasgos fisonómicos similares a los que reconoce en grupos humanos de su propio país. Se trata con estas alusiones de reproducir uno de los mitos dominantes en el siglo XVIII, el del «inmutable Oriente», ${ }^{28}$ es decir, el contraste entre la tendencia a la permanencia de los pueblos orientales y la atracción por el cambio y la novedad propia de la Europa occidental. ${ }^{29}$

25 Sarmiento, 2002, 550.

26 Ibidem.

27 Ibidem, 573 y 577.

28 Glacken, 1996, 512.

29 «Ya la vida pastoril nos vuelve impensadamente a traer a la imaginación el recuerdo del Asia, cuyas llanuras nos imaginamos siempre cubiertas aquí y allá de las tiendas del camulco, del cosaco o del árabe. La vida primitiva de los pueblos, la vida eminentemente bárbara y estacionaria, la vida de Abraham, que es la del beduino de hoy, asoma en los campos argentinos, aunque modificada por la civilización de un modo extraño» (Sarmiento, 2002, 553). 
En 1883 publica Conflictos y armonías de las razas en América, obra que no añade novedades sobre las ideas básicas que había mantenido décadas antes. ${ }^{30}$ Profundiza allí en el concepto de raza como mecanismo diferenciador y como forma de mantener la pureza frente a la degeneración provocada por la mezcla de etnias distintas. ${ }^{31}$ Ideas que estaban en el núcleo del determinismo naturalista de las culturas, tendencia que caracterizó la antropología física europea desde la década de 1840. La fe en la epistemología cientifista (positivismo), la creciente competitividad vinculada a la expansión industrial y el proceso colonizador y migratorio incrementaron el interés por el uso de la raza como categoría de distinción humana. ${ }^{32}$ Es en el período mencionado cuando aparecen las sociedades etnológicas y antropológicas en Inglaterra, Francia y Estados Unidos. Basándose esta vez en la retórica etnológica, en las clasificaciones y en observaciones de viajeros Sarmiento mantiene sus clásicas apreciaciones sobre la incapacidad de ciertas razas para contribuir al progreso, entendido en el sentido de progreso material. En sus referencias, lo físico y lo moral se entrecruzan, no hay separación: todos los indios en América se parecen físicamente y, por tanto, todos comparten los mismos vicios morales. ${ }^{33}$ Sus juicios y divisiones, acompañadas de las alusiones físicas tenían así, como los estudios de la antropología positivista, una apariencia científica. ${ }^{34}$ Pero igualmente legitiman las decisiones que conducen a su exterminio. ${ }^{35}$ Con la raza negra se acerca, en cambio, a la mentalidad liberal y muestra así sus deudas con las concepciones norteamericanas, sobre todo las utilitaristas del costebeneficio. ${ }^{36}$ La esclavitud, en este sentido, era una práctica inútil; la prohibición de esta institución favorecería la emergencia de un mercado de trabajo a bajo costo.

Estos tipos humanos contrastan con la figura del «europeo industrioso». Explica al final de Facundo que de Europa anualmente emigran medio

30 Por señalar sólo un ejemplo, seguía insistiendo en la desidia y apatía de los indios (tanto los de Louisiana y Canadá como los de Perú) y en su incapacidad para aprender (Sarmiento, 1883, 22); sobre los araucanos, ibídem, págs. 32 y ss.

31 El asunto sobre la degeneración derivada de la fusión ya contaba con una cierta tradición; entre los autores defensores de esta tesis y de la pureza racial destaca J. A. de Gobineau, Essai sur l' $i$ négalité des races humaines, París, 1853-1855 (Peset, 1983, 55-58).

32 Stocking, 1982, 38; Smith, 1997, 393 y 398-399.

33 Sarmiento, 1883, 23 y 24.

34 Solodkow, 2005, 103.

35 Recordemos la campaña del desierto del general Roca (1876-1879) durante la presidencia de Sarmiento.

36 Solodkow, 2005, 109. 
millón de personas con «una industria o un oficio». Hasta 1840 se han dirigido a Norteamérica, afirma, pero el número tan elevado de emigrantes ha provocado en algunas ciudades costeras un aumento de la población desproporcionado, factor que ha desencadenado una situación de miseria similar a la que tenían en Europa. Los emigrantes han buscado pues otros destinos. Una vez descartados México y Brasil, han recalado en Montevideo, primero, y en Buenos Aires, después. Sin embargo, aquí son empleados para ocupar el lugar de los miembros del ejército que mueren en los conflictos que mantiene Rosas. La «inmigración industriosa de la Europa» debe ocuparse, según nuestro autor, de otras tareas, entre ellas de las obras de ingeniería. Si Argentina recibiera cien mil personas al año, especula Sarmiento, se establecerían en el país en diez años un millón de europeos industriosos: ${ }^{37}$

\begin{abstract}
enseñándonos a trabajar, explotando nuevas riquezas, y enriqueciendo al país con sus propiedades; y con un millón de hombres civilizados la guerra civil es imposible, porque serían menos los que se hallarían en estado de desearla. La colonia escocesa que Rivadavia fundó al sur de Buenos Aires lo prueba hasta la evidencia; ha sufrido de la guerra, pero ella jamás ha tomado parte, y ningún gaucho alemán ha abandonado su trabajo, su lechería o su fábrica de quesos, para ir a corretear a la pampa.
\end{abstract}

Ese «gaucho alemán» nada tiene que ver con el gaucho que se desenvuelve en las condiciones de una naturaleza indómita. Son estos de «caras cerradas de barbas» $\mathrm{y}$ «con semblantes graves y serios»; son personas altivas y arrogantes que miran con desdén al habitante sedentario de la ciudad, que «nunca ha parado un tigre, recibídolo con el puñal en una mano y el poncho envuelto en la otra, para meterlo en la boca, mientras le traspasa el corazón y lo deja tendido a sus pies».$^{38}$ Según afirma el autor más tarde, «La vida en el campo, pues, ha desenvuelto en el gaucho las facultades físicas, sin ninguna de las de la inteligencia». ${ }^{39}$

Sarmiento especula con dos mecanismos para sustituir unos arquetipos por otros. Uno, el ya visto, es el de la inmigración. El otro es el de la educación. De las ventajas de la educación, especialmente de la adquisición de valores, excluye al indio por su «ineducabilidad» y los individuos de sangre mixta por ser «incapaces e inadecuados para la civilización». Estas alusiones han sido interpretadas como una consecuencia de sus conviccio-

37 Sarmiento, 2002, 781-782.

38 Ibidem, 558.

39 Ibidem, 559. 
nes liberales llevadas hasta el extremo. Para él, la expansión de una cultura desplaza y hace insostenible la supervivencia de otras. Así pues, lo que Sarmiento está reflejando es una combinación de presupuestos liberales y de ideas procedentes del darwinismo social, propuesta, esta última, que defendía un mundo donde los menos aptos tendrían que ceder ante quienes fueran más avezados a la hora de explotar los recursos naturales, establecer fábricas y controlar el comercio. ${ }^{40}$

En De la educación popular ocupa un lugar central lo que el autor denomina «el conocimiento aunque rudimentario de las ciencias y hechos necesarios para formar la razón»." Las naciones poderosas se forjan, según expone, promoviendo su fuerza industrial, moral e intelectual, y la vía para conseguir estos propósitos es la educación pública. ${ }^{42}$ Compuesta cuatro años después que Facundo, en De la educación sigue manteniendo argumentos ya familiares, como cuando afirma que los países iberoamericanos están condicionados por su pertenencia a una raza que «figura en última línea» dentro de ese orden de civilizaciones impuesto por el progreso. España y su herencia - tampoco esto sueña extraño- son los responsables de esa postergación. Los estereotipos siguen ocupando un lugar destacado en las categorías analíticas empleadas por Sarmiento. Un procedimiento que se emplea igualmente para elogiar las desproporcionadas capacidades de otros países, atribuciones que contribuyeron a crear el mito del genio ideal europeo o de la nación modelo, que se verá posteriormente. Las páginas siguientes de la extensa introducción explicativa están dedicadas a examinar casos que confirmen la relación entre la carencia de una formación primaria y la ineptitud para las tareas industriales. Ofrece como ejemplo dos fábricas de Santiago de Chile, donde los herreros que debían reparar las máquinas no comprendían su funcionamiento y los extranjeros que sí eran capaces pedían cantidades exorbitantes. Después alude a los testimonios de empresarios norteamericanos, británicos y franceses para apoyar sus tesis. Aquí insiste en el rasgo ya apuntado, el de los efectos morales que tiene esa clase de instrucción, cuya relevancia para el empresario es tan grande como la supuesta adquisición de habilidades, que muy probablemente se consiguen por medio de la experiencia en el seno de la fábrica y no por los conocimientos asimilados en las etapas iniciales

\footnotetext{
40 Katra, 1996, 853-912 y 886-886.

41 Sarmiento, 1849, 16.

42 Ibidem, 18-19.
} 
de la formación. En este apartado cita al abogado de Edimburgo George Combe (1788-1858), popularizador de la frenología, ${ }^{43}$ de quien le interesan especialmente sus afirmaciones sobre la disciplina moral y mental que se logra mediante la educación. De él destaca algunas declaraciones, como la que compara a los educados e instruidos alemanes en las escuelas prusianas con los «educados, inteligentes y enérgicos operarios de Manchester y Birmingham». ${ }^{44}$ Es decir, los valores de la civilización técnico-industrial se adquirían tanto mediante la asistencia a los centros apropiados como a través del trabajo en las fábricas.

Sobre la primera de las vías, la de la inmigración, al menos en Argentina, los movimientos de población procedentes de Europa siguieron unas tendencias diferentes a las previstas por Sarmiento. Entre 1857 y 1910, los países de procedencia dominantes fueron, en este orden, Italia y España, seguidos a una cierta distancia por Francia. De acuerdo con el trabajo de Blanca Sánchez Alonso, ${ }^{45}$ que añade las conclusiones de otros estudios, ${ }^{46}$ las personas procedentes de la Europa del Sur eran trabajadores no cualificados o con una cualificación baja. En el caso español, la mayoría eran agricultores y jornaleros y desempeñaron las profesiones más diversas, favorecidos por esa baja cualificación que facilitaba su incorporación a un mercado abierto como el argentino de las décadas anteriores a la Primera Guerra Mundial. Entre 1876 y 1895, en esa situación de trabajador no cualificado se encontraba el $89 \%$ de los italianos, que representaba un mayor porcentaje que los españoles (77\%), si bien en las décadas siguientes esta circunstancia se invirtió. Los italianos contaban con algunas ventajas en el proceso de integración en el mundo laboral, como las redes de apoyo y una información más precisa de las necesidades profesionales. Los españoles, por su parte, compensaban esas deficiencias con la ausencia de impedimentos por el idioma y una mayor alfabetización (en 1914, en torno al 25\% de la población española residente en Argentina era analfabeta, frente al $38 \%$ de los italianos).

43 La frenología atrajo la atención de Sarmiento, quien ya alude a Franz Joseph Gall y Johann Gaspar Spurzheim, iniciadores de esta técnica, en Facundo, civilización o barbarie. El propio Comte creía igualmente en las conclusiones de la frenología (Olson, 2008, 68).

44 Sarmiento, 1849, 32.

45 Sánchez, 2001.

46 T. J. Hatton y J. G. Williamson, The Age of Mass Migration. Causes and Economic Impact, Nueva York, Oxford University Press, 1998; J. C. Moya, Cousins and Strangers. Spanish Immigrants in Buenos Aires, 1850-1930, Berkeley, University of California Press, 1998. 
PROFESIONES DE LOS INMIGRANTES LLEGADOS

A ARGENTINA EN 1913 (en porcentajes)

\begin{tabular}{lccc} 
& Españoles & Italianos & Total de la población \\
\hline Agricultores & 11,7 & 32 & 20,5 \\
Jornaleros & 38,2 & 18,4 & 29,4 \\
Albañiles y carpinteros & 0,6 & 5,3 & 2,5 \\
Mecánicos & 0,1 & 0,9 & 0,7 \\
Comerciantes & 2,7 & 2,8 & 0,8 \\
Dependientes & 0,6 & 0,6 & 0,8 \\
Costureras y modistas & 3,8 & 3,4 & 3,9 \\
Planchadoras & 2,8 & 1,7 & 2,3 \\
Sirvientes/as & 6,1 & 11 & 7,8 \\
Sin profesión (niños) & 16,6 & 13,5 & 14,8 \\
Sin profesión (mujeres) & 5,5 & 3,1 & 4,1 \\
\end{tabular}

Fuente: Memoria del Ministerio de Agricultura (1915), en Blanca Sánchez Alonso (2001).

ALFABETIZACIÓN POR ORIGEN NACIONAL, 1914 (porcentajes)*

\begin{tabular}{lccc} 
& Argentinos & Españoles & Italianos \\
\hline Hombres & 61,1 & 78,7 & 67,3 \\
Mujeres & 59,7 & 55,2 & 52,4 \\
Total & 60,4 & 69,8 & 61,8
\end{tabular}

Fuente: Censo argentino, 1914, Tomo III, en Blanca Sánchez Alonso (2001).

* Mayores de 7 años.

En realidad, el personaje inventado por Sarmiento para revolucionar los cimientos culturales americanos, el supuesto individuo equipado con los valores arquetípicos de la laboriosidad europea no aparece como un sujeto decisivo en los cambios socio-económicos acaecidos en el último cuarto del siglo XIX. La transferencia de tecnología no es producto de la suma de aportaciones individuales, sino que tiene lugar en un marco en el que diversos países sudamericanos, entre ellos Argentina junto con Brasil y Uruguay, se consolidan como naciones exportadoras de productos agropecuarios. ${ }^{47}$

47 Nahm, 1997. 
Este fenómeno acontece en conjunción con los intereses empresariales derivados de la expansión comercial y de los propósitos de los países industrializados. La prioridad tecnológica más inmediata fue la relacionada con la obtención, transformación y transporte de los productos de exportación. En esta política adquirieron relevancia las instalaciones frigoríficas, las fábricas de conservas, los tostaderos de café, las refinerías de azúcar, las instalaciones para el tratamiento del caucho, las refinerías de petróleo, y todo tipo de instalaciones para la explotación minera, además de la colocación del trazado de líneas férreas. Posteriormente se atendió, por el aumento de complejidad de las economías, a infraestructuras como el transporte público, la telegrafía y el material eléctrico. Finalmente, el crecimiento de la población y de su nivel de vida influyó en el asentamiento de una industria de bienes de consumo. Por tanto, un cuadro más complejo que el imaginado por Sarmiento, que creía más en la fuerza de los valores arquetípicos que transferían los individuos pertenecientes a un colectivo diferenciado (el idealizado hombre del norte de Europa) que en la influencia de las condiciones externas, la adaptabilidad del ser humano a los nuevos entornos y los cambiantes intereses económicos y geoestratégicos de las grandes potencias.

\section{Naciones modelo}

A las antinomias ya señaladas, resumidas en el contraste civilización/barbarie, Sarmiento añade otras similares, como la de progreso/estancamiento y regresión/innovación, presentes en el pensamiento liberal iberoamericano del siglo $\mathrm{XIX}^{48} \mathrm{y}$ empleadas por nuestro autor para destacar las diferencias entre países tecnológicamente avanzados y los que se encuentran en una situación de atraso. Dice en De la educación popular:

Carecen ['España y sus descendientes'] de medios de acción, por su falta radical de aquellos conocimientos en las ciencias naturales o físicas, que en los demás países de Europa han creado una poderosa industria que da ocupación a todos los individuos de la sociedad, la producción; hija del trabajo, no puede hacerse hoy en una escala provechosa, sino por la introducción de los medios mecánicos que ha conquistado la industria en los otros países; y si la educación no prepara a las venideras generaciones, para esta necesaria adaptación de los medios de trabajo, el resultado será la pobreza y oscuridad nacional, en medio del desenvolvimiento de las otras naciones

48 Dávila, 2002, 65-108. 
que marchan con el auxilio combinado de tradiciones de ciencia e industria de largo tiempo echadas, y el desenvolvimiento actual obrado por la instrucción pública que les promete progresos y desarrollo de fuerzas productivas mayores. ${ }^{49}$

La década de 1840 fue para el autor un período de intensa labor en el terreno de la enseñanza y del pensamiento educativo, una tarea que había llevado a cabo en Chile huyendo de la política de Juan Manuel de Rosas en Argentina. Durante esa estancia, el Ministro de Instrucción Pública le encargó la dirección de la que es considerada como la primera escuela latinoamericana dedicada a la formación de maestros, la Escuela Normal de Preceptores (1842). En 1845, fue comisionado para viajar a Europa y Estados Unidos con el propósito de conocer los métodos aplicados en esos lugares y resolver los numerosos problemas que el nuevo centro estaba provocando. Las impresiones de ese periplo se reunieron en el ya citado De la educación popular y en extensas cartas dirigidas a amigos (reunidas en Viajes por Europa, África y América).

Francia ejerció, como bien es sabido, una poderosa influencia en diversas generaciones de intelectuales argentinos desde la Generación del 37. Su filosofía, historia, literatura, historiografía y política han estado presentes en las referencias de estos pensadores ocupados en la localización de modelos que sirvieran a los ideales emancipatorios y a la reconstrucción nacional. También menciona Sarmiento con devoción el «norte de Europa», de donde procede el individuo industrioso del que ya hemos hablado anteriormente. Pero si tuviéramos que seleccionar el icono más representativo de la tecnofilia sarmientina, la elección debería recaer en Estados Unidos. Diversas representaciones, acompañadas de antagonismos y referencias a la cultura material, conforman este símbolo de la cultura tecnológica y del progreso.

Las primeras líneas que resumen sus impresiones del país señalan abiertamente la posición del autor, cuando advierte que «Los Estados Unidos son una cosa sin modelo anterior» y dedica a continuación diversos epítetos como los de grandiosidad, nobleza y regularidad a la nación. ${ }^{50}$ Señala que ha visitado todas sus grandes ciudades y atravesado veintiuno de los estados más ricos. No va hacer, asegura, una descripción ordenada y comienza con alusiones a sus favorables condiciones naturales, indicando

49 Sarmiento, 1849, 21.

50 Sarmiento, «Estados Unidos. Carta a Valentín Alsina. Noviembre 12 de 1847», en Sarmiento, 2002, 421. 
los recursos que benefician las comunicaciones, el transporte de materias primas y el comercio. Las facilidades naturales se entremezclan con las acciones técnicas, donde destacan las referencias a las instalaciones de telegrafía eléctrica, sobre la que ofrece algunos datos acerca de su extensión y que representan un complemento básico para que los emigrantes ocupen las tierras: «ruedan torrentes humanos por entre las selvas primitivas, y la palabra pasa muda por sobre sus cabezas en hilos de hierro, para ir a activar a lo lejos aquella invasión del hombre sobre el suelo que le estaba reservado, [...]». ${ }^{51}$ También el ferrocarril completa las «líneas» que ya forman los lagos facilitando las comunicaciones rápidas y baratas, al alcance de todas las fortunas. A estas alusiones se suman otros resultados de la técnica que pueden observarse en las aldeas y en sus casas, «de ladrillo construido con el auxilio de máquinas, lo que da a sus costados la tersura de figuras matemáticas».$^{52}$ Es decir, una apreciación situada en las antípodas de lo que un partidario de fomentar las artes y los oficios y displicente a su vez con la industrialización, como John Ruskin, valoraba en la Inglaterra del siglo XIX..$^{53}$ Porque para Sarmiento la sociedad, que nace en los «bosques» es una consecuencia de la civilización y la máxima aspiración de sus componentes es tener cuanto antes, por un lado, «posta diaria, caminos, puertos, ferrocarriles, telégrafos, etc.», y por el otro, «de pieza en pieza» conseguir «el arado, el vestido, los utensilios de cocina perfeccionados, de patente, el último resultado de la ciencia humana para todos, para cada uno». ${ }^{54}$ Esta exuberancia material no se encuentra en Europa, según el autor. En el Viejo Continente ha visto «sus millones de campesinos, proletarios y artesanos viles, degradados, indignos de ser contados entre los hombres». ${ }^{55}$

Hay, para el autor argentino, otros objetos y megaconstrucciones que identifican igualmente la nación-modelo. En dos ocasiones habla, cuando hace comentarios sobre la vestimenta, de la afición del estadounidense por los relojes. En una de ellas afirma que «Los americanos en masa llevan reloj: en Francia no lo usa un décimo de la población». ${ }^{56}$ La consideración podría pasar inadvertida si no fuera por la relevancia que el mencionado artefacto ha tenido en la cultura occidental, puesta de manifiesto entre otros historiadores y pensadores por el filósofo de la tecnología Lewis Mumford

51 Ibidem, 428.

52 Ibidem, 430.

53 Sennett, «El artesano romántico», en Sennett, 2009, 135-149.

54 Sarmiento, 2002, 476.

55 Ibidem.

56 Sarmiento, 2002, 450. 
en Técnica y Civilización allá por 1934. El reloj, el afán por sincronizar las actividades laborales y sociales, adquiere, según las conclusiones de estos autores, una creciente importancia en el contexto de la expansión de la civilización industrial y de los sistemas fabriles. ${ }^{57}$ Lo que Sarmiento quiere decir con esa alusión es que los norteamericanos viven en una sociedad ordenada y disciplinada, valores que se consideran ejemplares. El autor se detiene igualmente en dos construcciones, una perteneciente a los transportes y la otra a la arquitectura urbana. De los transportes llama la atención sobre los barcos de vapor, que atraviesan parajes oscuros donde el viajero teme ser asaltado por «el último resto de las tribus salvajes». Se trata de «palacios flotantes de tres pisos, con galerías y azoteas para pasearse». ${ }^{58}$ Menciona el Issac Newton y el Hendrick, que mide este último $104 \mathrm{~m}$. de largo y que posee 600 camarotes y capacidad para 2000 pasajeros, todo por un dólar. ${ }^{59}$ De las ciudades destaca los «hoteles monstruo», en particular el Astor Hotel, que para Sarmiento significa la materialización del falansterio del socialista utópico Fourier. ${ }^{60}$ Su conclusión sobre estas «colosales construcciones americanas» es que son una muestra inequívoca de que Estados Unidos se encuentra en el lugar más avanzado de la civilización.

Para algún motivo, Sarmiento más bien actúa siguiendo un patrón predeterminado (ya lo había hecho en Facundo, donde la descripción de la pampa se había realizado sin haber pisado esas tierras), con una opinión formada previamente y eludiendo cualquier consideración crítica. En Estados Unidos el autor, en su búsqueda de fabricar una utopía, encontró alivio tras la impresión negativa y la crisis que le produjo la visita a Europa. ${ }^{61}$

\section{Santos laicos y vidas ejemplares}

Para Sarmiento, el científico y el ingeniero eran los héroes de la modernidad. Su atención a estos personajes se movía entre la ya consabida función redentora de la ciencia y la tecnología y el culto a la personalidad.

57 Thompson, 1967, 56-97.

58 Sarmiento, 2002, 436.

59 Ibidem, 437.

60 Ibidem, 444.

61 Katra, 1994, 88-94; Katra, 1996, 859, 863 y 877. «Aunque no hubiera encontrado allí los grandes hoteles, edificios y canales dignos de sus hipérboles, los habría inventado» (Ibidem, 883). La actitud crítica sí puede destacarse, sin embargo, en otros escritores, como en Alexis de Tocqueville, del que tomó varias ideas si bien sólo lo cita una vez. 
Esa admiración comenzó con el interés que mostró por Benjamin Franklin, al que leyó muy pronto, en 1826, mientras trabajaba en la tienda de su tía, y siguió posteriormente cuando se ocupó de otras figuras, como Charles Darwin o el paleontólogo Francisco Javier Muñiz, según veremos más tarde. También fue amigo entre otros del santsimoniano Ferdinand de Lesseps, responsable de la construcción del canal de Suez, cuyos servicios intentó conseguir para la reforma del puerto de Buenos Aires en su etapa presidencial. Lesseps representaba para Sarmiento, en sus elogiosas referencias al ingeniero, la imagen del emprendedor arquetípico. En similares términos menciona a Samuel Morse, cuyo telégrafo con sus largas cintas perforadas es un símbolo de velocidad, economía y precisión horaria. ${ }^{62}$

Franklin, al que cita tanto en Viajes ${ }^{63}$ como en Recuerdos de Provincias, es importante no sólo por sus estudios de electricidad y por ser el inventor del pararrayos, sino por su activismo político y por su concepción puritana de la ciencia y de la tecnología, así como de la vida. Diligencia, orden, esmero y dedicación a tareas útiles son algunas de las virtudes que pueden leerse como máximas en los apuntes autobiográficos del norteamericano, así como en «El camino a la riqueza» (donde, por ejemplo, aparece la siguiente expresión: «La pereza hace las cosas difíciles; la industria, fáciles»). ${ }^{64} \mathrm{Sin}$ duda, esta era la imagen que Sarmiento quería promover. $\mathrm{Su}$ identificación con el autor americano parece que alcanzó cotas elevadas, como muestra alguna expresión empleada en Recuerdos (autobiografía de 1850): «Yo me sentía Franklin», asegura; y añade: «Era yo pobrísimo como él, estudioso como él, y dándome maña y siguiendo sus huellas podía llegar a formarme como él, ser doctor ad honorem como él, y hacerme un lugar en las letras y en la política americana. La vida de Franklin debería formar parte de los libros de las escuelas primarias». ${ }^{65}$. Se ha llegado a afirmar que el «Franklin de los Recuerdos es Sarmiento mismo». ${ }^{66}$ Como cuando J. Bautista Alberdi escribe La vida y los trabajos industriales de William Wheelwright en la América del Sud (1876), la intención de Sarmiento es llamar la atención sobre un ejemplo didáctico y moral.

62 Viñas, 1994, 214-215.

63 En concreto, en el viaje a Estados Unidos; lo cita hasta en diez ocasiones, véase Katra, 1996, 860, n. 5 .

64 Franklin, 1993, 266.

65 Sarmiento, 2002, 944.

66 Altamirano y Sarlo, 1983, 24. 
En el acto organizado en el Círculo de Médicos de Buenos Aires en 1882 con motivo del fallecimiento de Charles Darwin, Sarmiento pronunció una conferencia en la que mostraba su adhesión a los principios de la teoría de la evolución. En ella dedica con el estilo exuberante habitual diversos elogios al científico y hace un particular repaso del devenir histórico en clave positivista, destacando progresos marcados por los acontecimientos científicos y técnicos. Cuando llega al siglo XIX, afirma:

Asistimos en esta época, a un período de observaciones profundas y de extensas meditaciones, afanándose el hombre en dar expresión á las leyes en virtud de las cuales la naturaleza, la sociedad y la vida misma funcionan y existen. Se hacen grandes, aunque no del todo fecundos esfuerzos, para escudriñar los secretos de la mente humana, y se reconstruye, piedra sobre piedra, la filosofía de la historia; pero las investigaciones más sagaces y profundas, tienen por campo las infinitas manifestaciones de la naturaleza, donde Darwin y sus discípulos han abierto nuevas y desconocidas rutas. ${ }^{67}$

En su exposición, el autor no se olvida de citar a los científicos procedentes de otros países a los que había facilitado su establecimiento en Argentina o contribuido a situar en cargos institucionales clave. Entre estos destacamos al astrónomo estadounidense B. Gould, que ocupó el puesto de director del Observatorio de Córdoba entre 1871 y 1885 , y al naturalista, geólogo y paleontólogo alemán K. Burmeister, director del Museo Público de Buenos Aires (1862-1892) y fundador de la Academia de Ciencias de Córdoba. Durante su etapa presidencial, Sarmiento también había impulsado el establecimiento del Jardín Zoológico de Buenos Aires. En 1888 fue nombrado director Eduardo L. Holmberg, el naturalista y escritor de ciencia ficción que acompañaba precisamente a Sarmiento seis años antes en la conferencia citada. Un análisis de sus discursos revela diferentes enfoques en la forma de interpretar y asumir la teoría de la evolución. Mientras Sarmiento manifestaba una aceptación incondicional de la doctrina darwiniana, porque prestaba argumentos a sus presupuestos positivistas del progreso indefinido - compartidos por Juan Bautista Alberdi y Bartolomé Mitre-, el joven Holmberg mantenía una posición escéptica y estrictamente científica a la hora de atender las consecuencias de la misma. ${ }^{68}$

La atención a Francisco Javier Muñiz presenta similares enfoques e intenciones. Como se sabe, Muñiz fue médico del Ejército y combatió, entre otras, en las campañas de la guerra contra la invasión inglesa de

67 Sarmiento, 1899. «Conferencia sobre Darwin».

68 Marún, 1995, 82-91. 
Buenos Aires y en las Guerras del Brasil. En 1825 comenzó sus observaciones de la flora y fauna argentinas, dedicándose especialmente a analizar fósiles de diversas especies. Encontró restos de varias especies extinguidas, algunas no estudiadas. Mantuvo correspondencia con Charles Darwin y es considerado el iniciador de la paleontología en Iberoamérica. Sus trabajos fueron compilados precisamente por Sarmiento.

Para Sarmiento, ocuparse de la figura de Muñiz era una contribución a la idea fundacional de crear una república de sabios e ingenieros en Argentina ${ }^{69}$ una idea que compartía con Alberdi. Según E. M. Vadell,${ }^{70}$ el propósito de Sarmiento al escribir esta obra es rescatar del olvido a un personaje que tiene un valor civilizador y arquetípico para la sociedad argentina, aunque carece en algunos momentos de su presentación del rigor que demanda un estudio sistemático. ${ }^{71}$ En la introducción de Vida y escritos del Coronel D. Francisco Javier Muñiz (1885) ${ }^{72}$ señala que para evitar presentarlo como héroe, tendencia común entre las biografías de la época, ofrecerá múltiples evidencias de sus trabajos, y así el lector podrá juzgar por sí mismo esa «figura que de simpática pasará a ser venerada». ${ }^{73}$ Más adelante hace un repaso de los méritos de Muñiz:

Como se verá por los documentos que nos sirven de guía, Muñiz tenía todas las intuiciones de las ideas que empiezan a agitar al mundo moderno. Practica la medicina y la cirugía por profesión; pero en la Universidad introduce y enseña las clases de obstetricia y las de patología infantil, mostrando al inaugurarlas el sentimiento del más alto respeto por la mujer, que ha principiado ya en otros países a reclamar la igualdad civil de los sexos, y a poco obtendrá el sufragio político. Muñiz preludia en ese camino. En el ejército introduce la alimentación vegetal y reclama los hospitales ambulantes, que son la última orden del día de los ejércitos modernos. En las ciencias naturales sigue las huellas de Darwin, continuando su obra y preparando materiales para el trabajo de clasificación que hará con más tecnicismo Burmeister, que lo reconoce uno de los estudiantes serios de la paleontología pampeana, desde aquellos tiempos. Llégale hoy su época, digámoslo así, al avestruz que entra bajo la égida protectora del hombre civilizado, resguardándolo de la extinción con que lo amenazaba la diaria persecución del salvaje. ${ }^{74}$

69 Botana, 1997, 428.

70 Vadell, 2007, 1-35.

71 «Sabe que la figura de Muñiz es un valor que hay que hacer perdurar» (Ibidem, 3).

72 El libro reúne textos acompañados de comentarios de los siguientes temas: la vacuna indígena; el ñandú o avestruz pampeano; las boleadoras; «ñata oxen» (nombre dado por Darwin a una variedad de vaca); paleontología argentina; escenas militares; el gaucho; cirugía; medicina legal; historia natural.

73 Sarmiento, $1885,7$.

74 Ibidem, 7-8. 
Por otra parte, celebra coincidir con el científico en las observaciones sobre los gauchos (de «instintos vagabundos y pendencieros») que él ya había expuesto en Civilización y barbarie. ${ }^{75} \mathrm{E}$ igualmente llama la atención, entre otros trabajos, sobre la descripción que Muñiz hace de las boleadoras, instrumento de caza empleado por los indígenas de la Pampa y por los gauchos. Para Sarmiento son ejemplos de técnicas primitivas, adaptadas a la naturaleza, «en vísperas de desaparecer ante la civilización que los hace inútiles». ${ }^{76} \mathrm{La}$ tecnología forzará un cambio en los diversos ritos, convenciones y habilidades; como había ocurrido con los artesanos europeos, la mecanización del telar forzará la desaparición de su forma de vida.

\section{Conclusión}

En las páginas anteriores se ha examinado cómo experimenta Sarmiento la tecnología. Para ello se han consultado las imágenes que construye de la naturaleza, las personas y los artefactos, donde predominan las representaciones antagónicas y los contrastes. Dice R. Bartra que «El hombre llamado civilizado no ha dado un solo paso sin ir acompañado de su sombra, el salvaje». ${ }^{77}$ Así, la imagen de un campo cultivado y cercado con alambre galvanizado o bien un paisaje atravesado por interminables postes que soportan hilos o una llanura surcada por vías de ferrocarril, señalan la oposición o la expulsión de una naturaleza hostil. La tecnología y la presencia humana se identifican, ya que la acción pobladora tiene como cometido someter y conquistar el entorno. Para Sarmiento, la imagen más poderosa de la domesticación son los espacios urbanizados, y dentro de ellos, los enormes hoteles, los «falansterios de Fourier», esas unidades autosuficientes o palacios que en la utopía del pensador francés se concebían como estructuras donde la arquitectura y las vías de comunicación internas aseguraban de manera eficaz el cumplimiento de los propósitos societarios.

Las clasificaciones raciales dirigen la mirada de Sarmiento sobre los humanos y sus divisiones culturales, contempladas como categorías autónomas insalvables y definidas por sus rasgos físicos. Imagina e inventa, basándose en datos de historiadores, a indios cuya fisonomía es muy similar

75 Ibidem, 8.

76 Ibidem, 10

77 Bartra, 2011, 12. 
aunque proceden de lugares distantes; «sólo varía la corpulencia según los parajes», dice en Conflictos y armonías de las razas en América. ${ }^{78}$ Pero en sus rostros hay mínimas diferencias, como cuando compara al gaucho («caras cerradas de barbas») con el «árabe asiático». Todos se distinguen de la «raza europea pura», caracterizada por su «blancura de cutis, los ojos azulados, la frente espaciosa y despejada». ${ }^{79}$ Porque, en definitiva, la percepción de Sarmiento es moral: los indios tienen una «naturaleza apática e indiferente». ${ }^{80} \mathrm{Su}$ insistencia en las semejanzas físicas sirve para consolidar los elementos morales y para eliminar cualquier atisbo de esperanza en la posibilidad de transmitir a ciertas poblaciones el «espíritu industrioso» propio de los científicos, tecnólogos y emprendedores.

Por último, la mirada hacia los artefactos está afectada por la admiración o por lo que el historiador de la tecnología David E. Nye llamó «la experiencia de lo sublime», entendida como una configuración emocional que emerge y legitima nuevas condiciones sociales y tecnológicas. ${ }^{81}$ Pero de igual manera, cuando enumera uno tras otro los objetos que captan su atención, se rinde ante el espectáculo de la exuberancia material. En este caso, junto al anterior propósito, Sarmiento está recreando la utopía del progreso material. Aquí, la abundancia y la impresión de libertad forman una simbiosis que fue defendida en países con predominio del capitalismo empresarial. La lógica de esta postura, como afirmó K. Marx, ha conducido a la aceptación del cambio tecnológico, de la novedad y de sus beneficios sociales. ${ }^{82}$ Según el filósofo de la tecnología Langdon Winner, esta mentalidad comenzó a imponerse en Estados Unidos a partir de la década de $1840 .^{83}$ Las personas, al margen de las obligaciones jerárquicas, se sentían libres para explotar los recursos disponibles, cuya accesibilidad y efectividad podía incrementarse con los instrumentos tecnológicos. «Los conflictos sociales - afirma Winner-, flagelo de la democracia en el mundo antiguo, podían evitarse en Estados Unidos debido a que las desigualdades

78 Sarmiento, 1883, 24.

79 Sarmiento, 2002, 556.

80 Sarmiento, 1883, 22.

81 Nye, 1994, xvii.

82 El ritmo frenético de la tecnología, es decir, la innovación, viene impuesto por las leyes de la plusvalía y de la acumulación constantes, así como por el cometido de eliminar a los competidores; según se recoge en el Manifiesto comunista, la burguesía no puede existir sin revolucionar constantemente los instrumentos de producción, y con ellos, las relaciones de producción y las sociales; los procesos industriales no son pues nunca definitivos.

83 Winner, 2008, 87-91. 
sociales no importarían mucho. La abundancia material haría que todos tuvieran lo suficiente para ser perfectamente felices. A la larga, los norteamericanos consideraron esta noción como una teoría de aplicación general: la empresa económica, impulsada por la maquinaria del progreso técnico, era la esencia misma de la libertad humana». ${ }^{84}$

Recibido el 20 de diciembre de 2012 Aceptado el 1 de octubre de 2013

\section{Bibliografía}

Altamirano, Carlos y Sarlo, Beatriz: Ensayos argentinos: de Sarmiento a la vanguardia, Buenos Aires, Centros Editor de América Latina, 1983.

Amaro Castro, Lorena: «La América reinventada. Notas sobre la utopía de la "civilización" en Argirópolis, de Domingo Faustino Sarmiento», Espéculo. Revista de estudios literarios, 25, Madrid, 2003 (consultado en línea: www.ucm.es/info/especulo/numero25/argiropo.html; fecha de consulta: 24 de marzo de 2012).

Bartra, Roger: El mito del salvaje, México, Fondo de Cultura Económica, 2011.

Botana, Natalio: La tradición republicana: Alberdi, Sarmiento y las ideas políticas de su tiempo, Buenos Aires, Edit. Sudamericana, 1997.

Dávila, Luis Ricardo: Formación y bases de la modernidad en Hispanoamérica (Ensayo de historia intelectual), Caracas, Consejo de Desarrollo Científico, Humanístico y Tecnológico/ Universidad de Los Andes/ Fondo Editorial Tropykos, 2002.

Echeverría, Esteban: La cautiva, en Obras escogidas, ed. de Beatriz Sarlo y Carlos Altamirano, Caracas, Biblioteca Ayacucho, 1991.

Franklin, Benjamin: Autobiography and other writings, ed. de O. Seavey, Oxford, Oxford University Press, 1993.

Glacken, Clarence J.: Huellas en la playa de Rodas. Naturaleza y cultura en el pensamiento occidental desde la Antigüedad hasta el siglo XVIII, Barcelona, Ediciones del Serbal, 1996 [1. ${ }^{a}$ 1967].

Gómez, Leila: Iluminados y tránsfugas: relatos de viajeros y ficciones nacionales en Argentina, Paraguay y Perú, Madrid, Iberoamericana, 2009.

Kasson, John F.: Civlizing the Machine. Technology and the Republican Values, 1776-1900, Nueva York, Hill and Wang, 1999.

Katra, William H.: «Rereading Viajes: Race, Identity, and National Destiny», en Tulio Halperín Donghi et alii, Sarmiento. Author of a Nation, Berkeley y Los Ángeles, University of California Press, 1994.

84 Ibidem, 89 
Katra, William H.: «Sarmiento en los Estados Unidos», en D. F. Sarmiento, Viajes por Europa, África y América. 1845-1847, coord. de Javier Fernández, París, Universidad de París X, 1996, 853-912.

Larrain, Jorge: Identity and modernity in Latin America, Cambridge, Polity Press, 2005.

Marún, Gioconda: «Darwin y la literatura argentina del siglo XIX», Actas del XII Congreso de la Asociación Internacional de Hispanistas, vol. 7, Birmingham, 21-26 de agosto, 1995, 82-91.

Marx, Leo: The Machine in the Garden. Technology and the Pastoral Ideal in America, Oxford, Oxford University Press, 1964.

Nahm, Gerardo: «Las inversiones extranjeras y la transferencia de tecnología entre Europa y América Latina: el ejemplo de las grandes compañías eléctricas alemanas en Argentina», Scripta Nova. Revista Electrónica de Geografía y Ciencias Sociales, 1, Barcelona, 1997 (consultado en línea: http://www.ub.edu/geocrit/nova1.htm; fecha: 10 de mayo de 2012).

Nye, David E.: American Technological Sublime, Cambridge (Massachusetts), The MIT Press, 1997.

Olson, Richard G.: Science and Scientism in Nineteenth-Century Europe, Urbana y Chicago, University of Illinois Press, 2008.

Pacey, Arnold: El laberinto del ingenio. Ideas e idealismo en el desarrollo de la tecnología, Barcelona, Gustavo Gili, 1980.

Peset, José Luis: Ciencia y marginación. Sobre negros, locos y criminales, Barcelona, Crítica, 1983.

Rama, Carlos M.: «El utopismo socialista en América Latina», prólogo a Utopismo Socialista, Caracas, Biblioteca Ayacucho, 1977.

Reggini, Horacio C: La obsesión del hilo. Sarmiento y las telecomunicaciones, Buenos Aires, Ediciones Galápago, 1997.

Sánchez Alonso, Blanca: «La inmigración española en Argentina, siglos XIX y XX: capital humano y familias», Actas del VII Congreso de la Asociación de Historia Económica, Zaragoza, 2001.

Sarlo, Beatriz: La imaginación técnica. Sueños modernos de la cultura argentina, Buenos Aires, Nueva Visión, 2004.

Sarmiento, Faustino, «Aspecto físico de la República Argentina, y caracteres, hábitos e ideas que engendra», ed. de Diana Sorensen, Obras selectas, Madrid, Espasa Calpe, 2002.

Sarmiento, Domingo Faustino: De la educación popular, Santiago, 1849.

Sarmiento, Domingo Faustino: Conflictos y armonías de las razas en América, Buenos Aires, 1883.

Sarmiento, Domingo Faustino: Vida y escritos de Francisco Javier Muñiz, Obras de D. F. Sarmiento, Buenos Aires, 1885. 
Sarmiento, Domingo Faustino: «Conferencia sobre Darwin», 1882, en Obras Completas D. F. Sarmiento, ed. de Luis Montt y Augusto Belin Sarmiento, 1899, vol. XXII.

Sarmiento, Domingo Faustino: Obras selectas, ed. de Diana Sorensen, Madrid, Espasa Calpe, 2002.

Sennett, Richard: El artesano, Barcelona, Anagrama, 2009.

Schaffer, Simon: «Babbage's Intelligence: Calculating Engines and the Factory System», Critical Inquiry, 21, Chicago, 1994, 203-216.

Scheines, Graciela: Las metáforas del fracaso. Sudamérica, ¿geografía del desencuentro?, La Habana, Casa de las Américas, 1991.

Smith, Roger: The Fontana History of Human Sciences, Londres, The Fontana Press, 1997.

Solodkow, David: «Racismo y Nación: Conflictos y (des)armonías identitarias en el proyecto nacional sarmientino», Decimonónica, 2, 1, 2005, 95-121 (consultado en línea: http://www.decimononica.org/archives/vol2.htm; fecha: 3 de diciembre de 2011)

Sorensen, Diana: «Introducción», en Diana Sorensen, ed., Domingo Faustino Sarmiento, Obras selectas, Madrid, Espasa Calpe, 2002.

Stocking, George W.: Race, culture, and evolution, Chicago, University Press, 1982.

Thompson, Edward P.: «Time, Work-Discipline, and Industrial Capitalism», Past and Present, 38, Oxford, 1967, 56-97.

Urteaga, Luis: La tierra esquilmada. Las ideas sobre la conservación de la naturaleza en la cultura española del siglo XVIII, Madrid, CSIC, 1987.

Vadell, Eduardo M.: «Francisco Javier Muñiz en el pensamiento sarmientino», en www.ambasamericas.net, 2007, 1-35 (consultado el 23 de noviembre de 2011).

Viñas, David: «Sarmiento: Madness or Accumulation», en Tulio Halperín Donghi et alii, Sarmiento. Author of a Nation, Berkeley y Los Ángeles, University of California Press, 1994.

Winner, Langdon: La ballena y el reactor. Una búsqueda de los límites en la era de la alta tecnología, Barcelona, Gedisa, 2008.

Zea, Leopoldo: El pensamiento latinoamericano, Barcelona, Ariel, 1976. 